\section{Estudo \\ CoDebate}

em Testão

Plamejamento
Revista Estudo \& Debate, Lajeado, v. 27, n. 3, 2020. ISSN 1983-036X

DOI: http://dx.doi.org/10.22410/issn.1983-036X.v27i3a2020.2527

\title{
ANÁLISE ESPACIAL DA PRODUTIVIDADE DA MANDIOCA NOS MUNICÍPIOS PARANAENSES NOS ANOS 2009, 2013 E 2017
}

\author{
José Rodrigo Gobi ${ }^{1}$, Raoni Felipe Almeida André2, Ednaldo Michellon ${ }^{3}$
}

\begin{abstract}
Resumo: $\mathrm{O}$ estado do Paraná vem se destacando no cenário nacional em relação à produção de mandioca, pois é o segundo maior produtor da cultura, sendo que em 2017 atingiu $17,4 \%$ da produçáo nacional. Assim, o objetivo desta pesquisa foi analisar o padrão de associação espacial da produtividade da mandioca em relação à terra no estado do Paraná nos anos 2009, 2013 e 2017. Observou-se que a média da produtividade da mandioca está aumentando no estado, mesmo estando concentrada em algumas regiốes. A análise espacial permitiu verificar que com o passar do tempo a produtividade se concentra nas regióes Oeste, Noroeste e Norte, por conta da presença das indústrias de farinha e fécula. Nas demais regióes do estado, notou-se a predominância de clusters com baixa produtividade, pois nessas áreas a produção de mandioca tende a ser destinada para o consumo humano ou de animais. Além disso, os resultados da análise bivariada inferem que os dados apresentam autocorrelação espacial temporal, ou seja, o tempo também influencia a estrutura dos dados. Portanto, é importante ressaltar a importância das indústrias de féculas e farinhas nas regiốes Oeste, Noroeste e Norte paranaense para o alto nível de produtividade da cultura da mandioca no estado, sendo necessário encontrar mecanismos para aumentar a produtividade nas demais regióes.
\end{abstract}

Palavras-chave: Fécula. Produtividade da terra. Agricultura familiar. Paraná

\section{SPATIAL ANALYSIS OF CASSAVA PRODUCTIVITY IN PARANA MUNICIPALITIES IN THE YEARS 2009, 2013 AND 2017}

\begin{abstract}
The state of Paraná has been standing out on the national scene in relation to cassava production, as it is the second largest producer of culture, and in 2017 it reached $17.4 \%$ of national production. Thus, the objective of this research was to analyze the spatial association pattern of cassava productivity in relation to land in the state of Paraná in 2009, 2013 and 2017. It was observed that the average cassava productivity is increasing in the state, even though it is concentrated in some regions. Spatial analysis showed that over time productivity is concentrated in the West, Northwest and North regions, due to the presence of flour and starch
\end{abstract}

1 Doutorando do Programa de Pós-Graduação em Ciência Econômicas pela Universidade Estadual de Maringá (PCE/UEM). E-mail: joserodrigogobi@gmail.com.

2 Doutorando do Programa de Pós-Graduação em Ciência Econômicas pela Universidade Estadual de Maringá (PCE/UEM). E-mail: raoni07@hotmail.com.

3 Professor Associado ao Programa de Pós-Graduação em Ciências Econômicas da Universidade Estadual de Maringá (PCE/UEM).E-mail: emichellon@uem.br. 
industries. In other regions of the state, there was a predominance of clusters with low productivity, because in these areas' cassava production tends to be destined for human or animal consumption. In addition, the results of the bivariate analysis infer that the data show temporal spatial autocorrelation, i.e., time also influences the data structure. Therefore, it is important to emphasize the importance of starch and flour industries in the West, Northwest and North Paraná regions for the high level of cassava crop productivity in the state, and it is necessary to find mechanisms to increase productivity in other regions.

Keywords: Starch. Land productivity. Family farming. Paraná.

\section{INTRODUÇÃO}

A mandioca (Manihot Esculenta Crantz) é comercializada em forma de produto hortícola, largamente consumido no Brasil e no mundo. O mercado brasileiro dessa cultura vem crescendo nos últimos anos tanto para o consumo interno como para a exportação, sendo geralmente comercializada in natura ou pouco processada (AGUIAR et al., 2011).

A cultura da mandioca é importante pela sua boa adaptabilidade em diferentes condições ambientais, rusticidade e baixa exigência de fertilidade, além da sua alta aceitação na culinária, tornando-a a terceira maior fonte de alimento nas regióes tropicais, após o arroz e o milho (ALVES, 2002; FAOSTAT, 2019).

Entre as culturas energéticas a mandioca é a de mais fácil produção para o consumo doméstico por exigir pouca mão-de-obra e apresentar boa adaptação a solos com diferentes nutrientes (SILVA et. al., 2012). Por conta disso, o cultivo de mandioca é uma atividade de grande importância socioeconômica, principalmente para famílias de baixa renda que vivem em regiōes de clima tropical (IBGE, 2009).

No Brasil o cultivo é realizado em todos os estados da federação. No ano de 2017 a produçáo brasileira atingiu um total de 20,71 milhôes de toneladas de raízes de mandioca em 2,16 milhóes hectares de área plantada. O estado do Paraná, neste mesmo período, produziu por volta de 3,3 mil toneladas de mandioca, utilizando cerca de 139,4 mil hectares de área plantada, com produtividade média de 13,8 tonelada por hectare. É importante destacar que grande parte do cultivo paranaense está concentrado na agricultura familiar (IBGE, 2019).

Sob esse contexto, as pesquisas relacionadas à mandioca vêm se destacando em razão da facilidade do cultivo, expressiva produção e seu papel na estrutura socioeconômica. Portanto, diversos trabalhos buscam verificar os principais determinantes da produtividade da mandioca, tais como Silva et. al. (2009) e Modesto Junior et. al. (2009) que analisam os aspectos do cultivo de mandioca no âmbito brasileiro, e Vidigal Filho et al. (2000) e Biffe et al. (2010) para o estado do Paraná.

Devido à relevante participaçáo do Paraná na produção de mandioca e a importância da cultura na agricultura familiar, a presente pesquisa tem como objetivo geral analisar o padrão de associação espacial da produtividade da mandioca em relação à terra nesse estado nos anos 2009, 2013 e 2017. Especificamente, pretendeu-se investigar a autocorrelaçấo nos dados e a formação de clusters da produtividade no período. Além disso, buscam-se as possíveis explicaçóes para a formação dos agrupamentos encontrados. 
Este artigo está composto por mais quatro seçôes além desta introdução. A segunda seção aborda a revisão de literatura acerca do comércio e da produtividade da mandioca no Brasil e no mundo. A terceira seção contempla a metodologia que é utilizada no trabalho, composta pela base de dados, o modelo utilizado e a formaçáo dos índices de análise. $\mathrm{Na}$ quarta seção, os resultados obtidos são analisados por meio dos indicadores estatísticos e pela Análise Exploratória de Dados Espaciais (AEDE) para a produtividade da mandioca em relaçáo à terra no Paraná. Por fim, na quinta seção têm-se as principais conclusóes sobre produtividade da mandioca no estado.

\section{REVISÁO DE LITERATURA}

\subsection{Mercado da Mandioca}

A produção mundial de mandioca apresentou crescimento contínuo de 2009 a 2016, quando atingiu 296 milhóes de toneladas. Esse crescimento pode ser explicado, principalmente, pela mandioca ter se tornado alimento de segurança nacional para alguns países do continente Africano (GROXKO, 2017). Ademais, outra razão seria a forte resistência às intempéries climáticas, como as secas, permitindo a difusão dessa cultura em terras africanas (HOWELER; LUTALADIO; THOMAS, 2013; GROXKO, 2017).

$\mathrm{Na}$ Tabela 1 está demonstrado o comparativo da produçấo de mandioca entre os cinco maiores produtores mundiais. Verifica-se que a produção mundial cresceu aproximadamente $24,89 \%$ entre 2009 e 2017 . Os países Nigéria e Tailândia apresentaram os melhores desempenhos no período analisado, produzindo cerca de $31 \%$ da mandioca no mundo. A Nigéria exibiu crescimento acelerado a partir do ano de 2014, enquanto que o Brasil vem apresentando tendência de queda desde esse ano.

Tabela 1. Comparativo da produção de mandioca entre os cinco maiores produtores mundiais - 2009 a 2017

\begin{tabular}{crrrrrrrrr}
\hline \multirow{2}{*}{ País } & \multicolumn{10}{c}{ Produçáo (em mil toneladas) } \\
\cline { 2 - 10 } Nigéria & 2009 & 2010 & 2011 & 2012 & 2013 & 2014 & 2015 & 2016 & 2017 \\
Tailândia & 30.082 & 42.533 & 46.190 & 50.950 & 47.407 & 56.328 & 57.643 & 59.566 & 59.486 \\
Indonésia & 22.039 & 23.918 & 21.912 & 29.848 & 30.227 & 30.022 & 32.358 & 31.161 & 30.973 \\
Brasil & 24.404 & 24.967 & 25.344 & 24.177 & 23.937 & 23.436 & 21.801 & 20.745 & 19.046 \\
Gana & 12.231 & 13.504 & 14.241 & 14.044 & 21.484 & 23.253 & 23.060 & 21.084 & 18.876 \\
\hline Mundo & 233.794 & 239.296 & 251.822 & 277.683 & 278.990 & 17.798 & 17.213 & 17.798 & 18.471 \\
\hline
\end{tabular}

Fonte: Elaborado pelos autores a partir dos dados da FAOSTAT (2019).

Conforme demonstrado na Tabela 1 a produçáo brasileira de mandioca vem se reduzindo entre 2014 e 2017. Essa queda pode estar associada a estiagem que atingiu boa parte das regiốes produtoras do país (COÊLHO, 2018). Em 2017, a produção nacional atingiu 18,9 milhóes de toneladas de mandioca, numa área plantada estimada de 1,33 milhão de hectares. Nesse ano o Brasil ocupava a quarta posição entre os maiores produtores mundiais dessa cultura. 
A cultura da mandioca no Brasil é caracterizada pelo seu consumo voltado ao mercado interno, com pouca representatividade no comércio internacional. Dessa forma, quando a produção mundial atinge grandes volumes, acaba fragilizando com facilidade os preços no mercado nacional (GROXKO, 2017).

No entanto, mesmo sendo caracterizada principalmente pelo consumo interno, a cultura da mandioca vem exibindo cada vez maior importância econômica, tendo apresentado de 2009 a 2017 grande crescimento do valor bruto da produção, sendo neste último ano superior a 11,1 bilhôes de reais (Figura 1).

Figura 1. Valor Bruto da Produção de mandioca em 2009, 2013 e 2017 - R\$ milhares

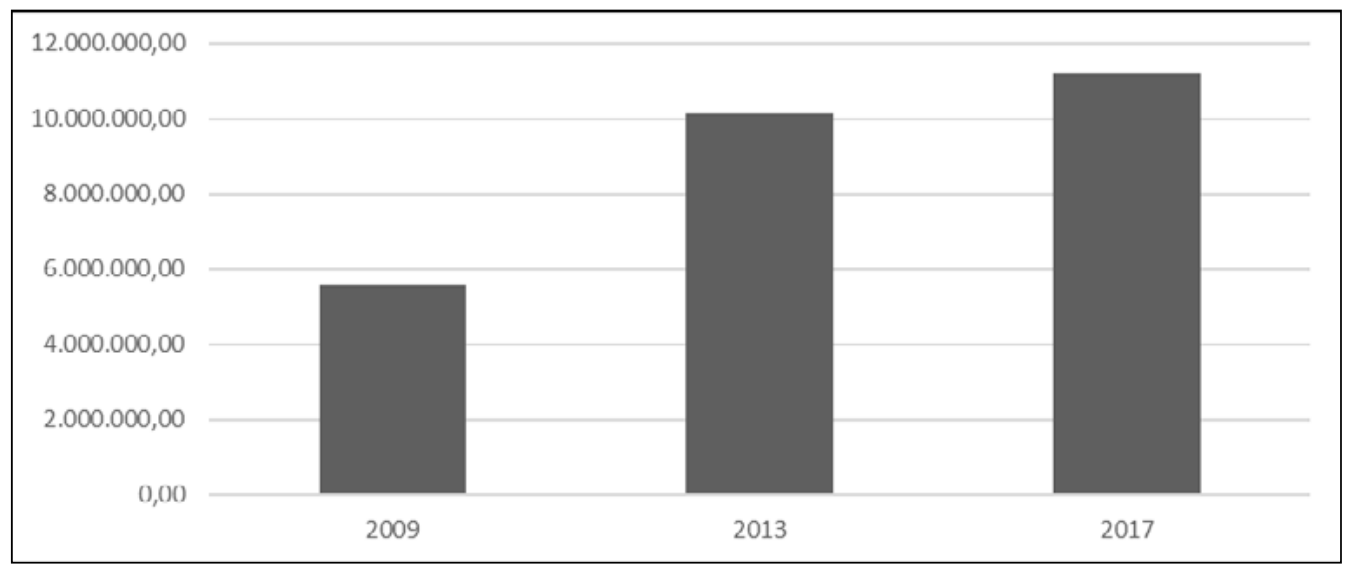

Fonte: Elaborado pelos autores a partir dos dados do IBGE (2019).

Em termos regionais (Tabela 2), observa-se que a região Norte brasileira apresenta a maior produçáo de mandioca em 2017 , com $38,21 \%$ da safra nacional, seguida por Sul com $25,25 \%$, Nordeste $20,56 \%$, Sudeste $9,7 \%$ e Centro-Oeste $6,28 \%$. A regiāo Nordeste liderou a produção dessa cultura no ano de 2009, perdendo a posição já em 2013 para a região Norte. Cabe destacar a região Sul, que exibiu a segunda maior produção dessa cultura já em 2013. 
Tabela 2. Produção e área plantada de mandioca nas Unidades da Federação, 2009, 2013 e 2017

\begin{tabular}{|c|c|c|c|c|c|c|}
\hline \multirow{2}{*}{ Unidade da Federação } & \multicolumn{3}{|c|}{ Produçáo (mil toneladas) } & \multicolumn{3}{|c|}{ Área plantada (mil hectares) } \\
\hline & 2009 & 2013 & 2017 & 2009 & 2013 & 2017 \\
\hline Norte & $7.147,0$ & $7.467,9$ & $7.212,8$ & 493,4 & 506,9 & 474,6 \\
\hline Rondônia & 499,9 & 446,7 & 658,3 & 29,7 & 28,4 & 29,2 \\
\hline Acre & 561,5 & 939,2 & 873,8 & 30,0 & 44,4 & 34,7 \\
\hline Amazonas & 995,9 & 941,0 & 969,3 & 97,4 & 96,0 & 84,7 \\
\hline Roraima & 77,2 & 140,3 & 80,7 & 6,2 & 82,2 & 55,2 \\
\hline Pará & $4.548,7$ & $4.621,7$ & $4.234,8$ & 298,1 & 302,3 & 294,3 \\
\hline Amapá & 116,6 & 134,7 & 166,6 & 10,3 & 11,9 & 12,9 \\
\hline Tocantins & 347,2 & 244,3 & 229,2 & 21,7 & 15,7 & 13,2 \\
\hline Nordeste & $8.178,4$ & $4.803,2$ & $3.881,9$ & 819,1 & 591,5 & 467,6 \\
\hline Maranhão & $1.216,4$ & $1.325,3$ & $1.315,9$ & 188,3 & 191,0 & 151,1 \\
\hline Piauí & 529,7 & 156,3 & 262,6 & 60,2 & 38,1 & 37,1 \\
\hline Ceará & 686,3 & 300,3 & 476,2 & 104,0 & 66,9 & 56,3 \\
\hline Rio Grande do Norte & 587,2 & 80,7 & 140,2 & 52,3 & 8,1 & 13,4 \\
\hline Paraíba & 262,1 & 135,1 & 146,2 & 27,7 & 15,2 & 15,5 \\
\hline Pernambuco & 655,9 & 292,8 & 197,4 & 59,5 & 39,9 & 28,6 \\
\hline Alagoas & 312,2 & 224,8 & 377,2 & 22,2 & 18,4 & 34,1 \\
\hline Sergipe & 491,4 & 433,7 & 248,8 & 33,1 & 28,7 & 18,9 \\
\hline Bahia & $3.437,1$ & $1.854,3$ & 717,2 & 271,6 & 185,0 & 112,4 \\
\hline Sudeste & $2.236,3$ & $2.491,2$ & $1.830,3$ & 127,7 & 136,8 & 101,2 \\
\hline Minas Gerais & 864,2 & 815,0 & 497,9 & 56,8 & 60,5 & 35,6 \\
\hline Espírito Santo & 259,5 & 157,7 & 120,3 & 15,2 & 9,2 & 7,7 \\
\hline Rio de Janeiro & 130,6 & 195,3 & 142,3 & 9,5 & 12,9 & 11,7 \\
\hline São Paulo & 982,1 & $1.323,0$ & $1.069,7$ & 46,1 & 54,0 & 46,1 \\
\hline Sul & $5.488,8$ & $5.477,4$ & $4.765,3$ & 273,3 & 257,4 & 220,8 \\
\hline Paraná & $3.654,7$ & $3.759,7$ & $3.288,3$ & 153,1 & 156,2 & 139,4 \\
\hline Santa Catarina & 552,2 & 551,3 & 410,2 & 36,5 & 28,6 & 21,4 \\
\hline Rio Grande do Sul & $1.281,9$ & $1.166,4$ & $1.066,8$ & 83,7 & 72,6 & 60,0 \\
\hline Centro-Oeste & $1.353,5$ & $1.244,4$ & $1.186,2$ & 83,5 & 67,6 & 65,2 \\
\hline Mato Grosso do Sul & 459,0 & 721,9 & 690,7 & 23,7 & 33,1 & 31,8 \\
\hline Mato Grosso & 525,6 & 335,7 & 277,0 & 36,9 & 23,2 & 19,1 \\
\hline Goiás & 355,3 & 166,6 & 201,1 & 21,9 & 10,0 & 13,3 \\
\hline Distrito Federal & 13,6 & 20,2 & 17,4 & 0,9 & 1,3 & 1,0 \\
\hline Brasil & $24.404,0$ & $21.484,2$ & $18.876,5$ & $1.797,0$ & $1.560,3$ & $1.330,0$ \\
\hline
\end{tabular}

Fonte: Elaborado pelos autores a partir de dados do IBGE (2019).

As regióes Nordeste e Norte produziram, em 2017, aproximadamente 58,8\% da produção nacional de mandioca $(\mathrm{t})$ em $70,8 \%$ das áreas plantadas (ha), no entanto, apresentam baixa eficiência produtiva $(\mathrm{t} / \mathrm{ha})$, ou seja, as menores taxas de produtividade do país, em torno de 8,3 t/ha e 15,2 t/ha, respectivamente (Figura 1). Por outro lado, a regiáo Sul, com cerca de $25,2 \%$ da produção nacional da cultura em 16,6\% das áreas plantadas 
em 2017, possuí o maior índice de produtividade do país, exibindo rendimento de 21,58 t/ha de mandioca plantada.

Figura 2. Evolução da produtividade (t/ha) de mandioca nas regiōes do Brasil - 2009 a 2017

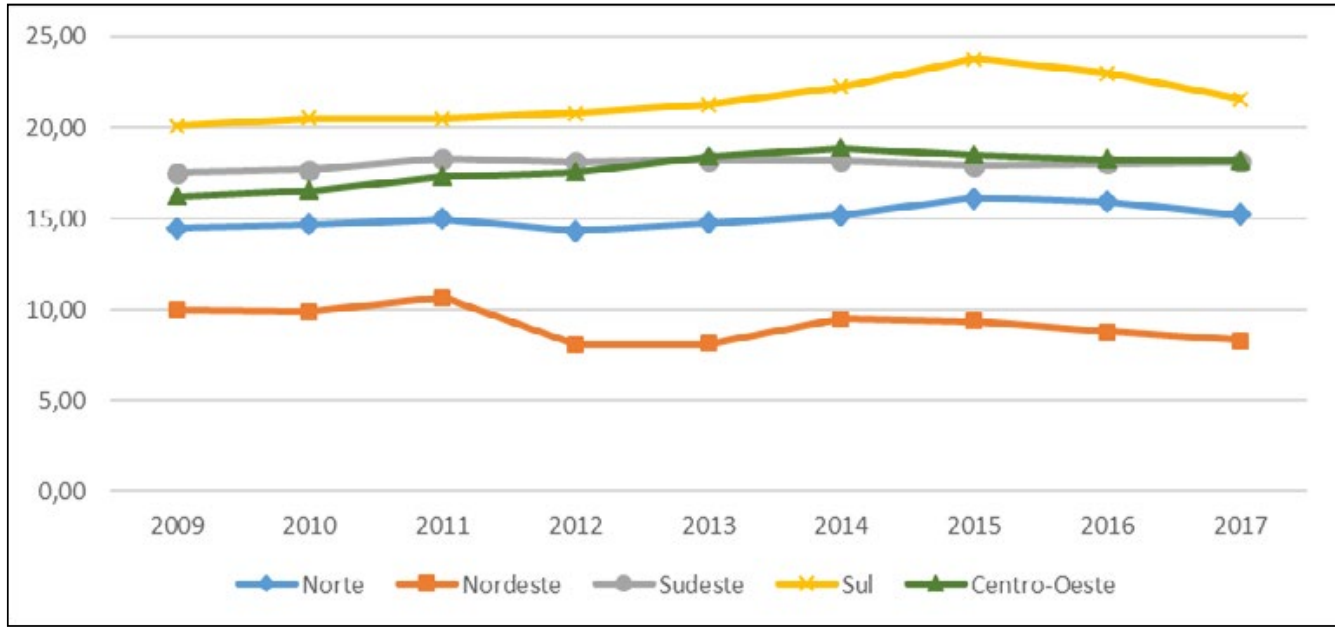

Fonte: Elaborado pelos autores a partir dos dados do IBGE (2019).

A maior produção estadual de mandioca em 2017 (Tabela 2) pertence ao estado do Pará com 22,4\% da produção nacional. Entretanto, apesar de manter grandes áreas plantadas $(22,1 \%$ do país) e grande produção de mandioca, demonstra baixa performance em seus rendimentos de mandioca plantada, apenas 14,39 t/ha (Figura 2). Por outro lado, o Acre apresenta a sétima maior produção nacional (4,63\%), mas vem apresentando grande crescimento ao longo dos anos, liderando os índices de eficiência produtiva em 2017, com 25,18 t/ha. 
Figura 3. Evolução da produtividade (t/ha) de mandioca em cinco estados do Brasil - 2009 a 2017

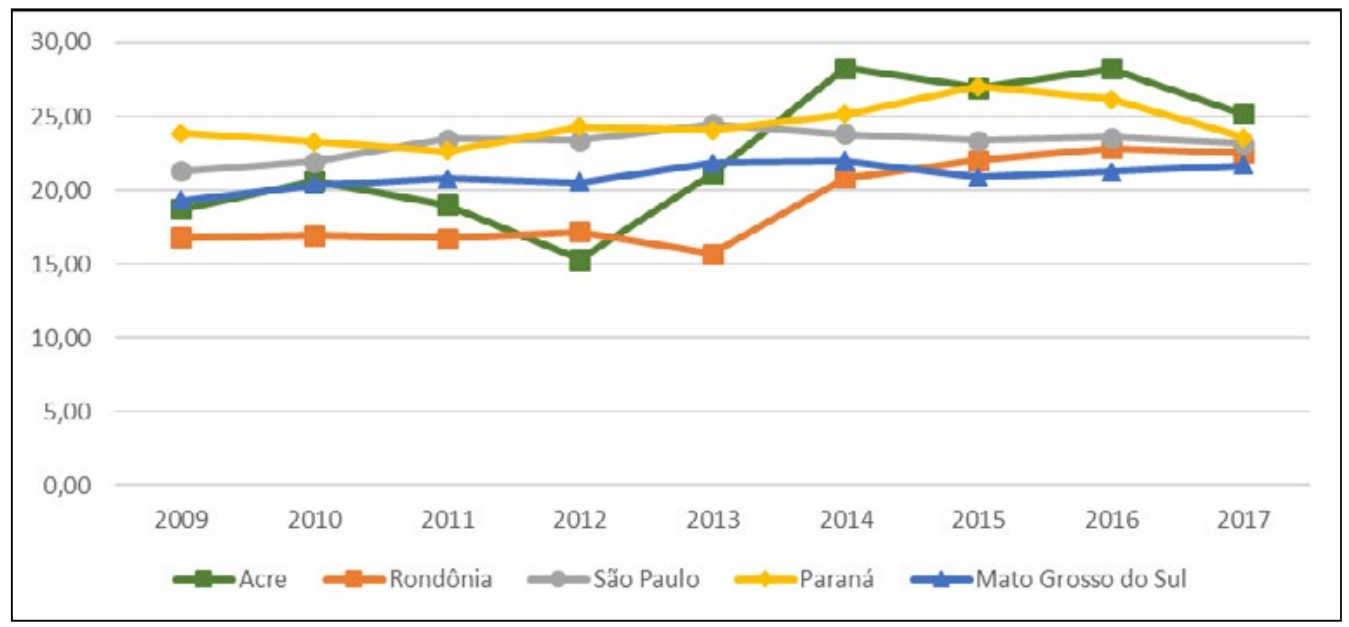

Fonte: Elaborado pelos autores a partir dos dados do IBGE (2019).

O Paraná destaca-se dentro da cadeia produtiva de mandioca tanto regionalmente quanto nacionalmente, seja na parte agrícola ou no segmento industrial. $\mathrm{O}$ estado foi o segundo maior produtor dessa cultura em 2017, com cerca de $17,4 \%$ da fatia nacional (Tabela 2). Além disso, tem se sobressaído na produção de farinha e fécula ${ }^{4}$. Este último é um dos produtos mais importantes da mandioca, por conta da maior possibilidade de agregação de valor e de exportação (COÊLHO, 2018).

Mesmo exibindo leve queda da produtividade nos últimos dois anos analisados, o Paraná tem mostrado crescimento consistente, registrando a segunda maior produtividade nacional, com aproximadamente 23,59 t/ha em 2017 (Figura 2). Esse avanço na produtividade tem forte relaçáo com os avanços significativos no setor industrial do estado, principalmente no segmento da fécula (GROXKO, 2016).

A cultura da mandioca no estado do Paraná é semelhante à do Brasil, com presença em praticamente todos os municípios, sendo o cultivo mais intensivo em tecnologia e com maiores áreas de produção se concentrando nas regiōes Norte, Oeste e Noroeste do estado. Estas regióes possuem importante parque industrial, com 42 fábricas de féculas e cerca de 50 farinheiras. Destaca-se que aproximadamente $70 \%$ da produção de mandioca no estado são destinadas para a fabricação de féculas, polvilho azedo e farinha (GROXKO, 2017).

A mandioca é cultivada em praticamente todos os demais municípios paranaenses, mas com menor escala de produção e menor área de lavouras. Nesses locais a produção

4 A fécula, amido ou polvilho de mandioca é um pó branco sem cheiro ou sabor comercializada tanto para o uso doméstico quanto industrial. Este produto pode ser usado para dar consistência em alimentos (como molhos, sopas, pudins e sorvete) e na produção de embutidos, perfumes, adesivos, papel e cola (COÊLHO, 2018). 
tende a ser destinada para o consumo humano ou de animais e a comercialização sendo praticada em supermercados e/ou em feiras livres. Por conta disso, essas lavouras acabam empregando baixos níveis de tecnologia, acarretando menor produtividade (GROXKO, 2017).

Nas áreas em que a produção é destinada para o abastecimento das fábricas de fécula e farinha é necessária a produção em larga escala, e as lavouras empregam níveis maiores de tecnologia. Os produtores realizam análise do solo, utilizam ramas de mandioca selecionadas para o plantio, adubação adequada e procuram receber orientaçóes de técnicos especializados. Nestas regióes com a mandioca voltada para o segmento industrial é onde se encontram as lavouras com maiores produtividades (GROXKO, 2016).

\subsection{Evidências Empíricas}

A cultura da mandioca destaca-se na agropecuária paranaense pelo seu papel na geração de emprego e renda. Em 2019, o estado do Paraná concentra cerca de 16,61\% da produção de mandioca do país, sendo o segundo maior produtor do Brasil. A maior parte da produção brasileira de mandioca está localizada na Região Norte com 38,53\% (IBGE, 2020).

Em vista disso, pesquisas relacionadas à produtividade média da mandioca vêm se destacando no cenário nacional, como Silva et al. (2009) que buscaram avaliar o crescimento da produção de mandioca em cultivos consorciado no sistema de agroprodução e, Modesto Junior et al. (2009), que avaliaram a produtividade de mandioca obtida por agricultores familiares utilizando capinas e plantio em espaçamentos definidos.

No estado paranaense também vêm sendo desenvolvidos estudos relacionados à produtividade da mandioca, tais como Biffe et al. (2010) que avaliaram os períodos de interferência das plantas daninhas na cultura da mandioca e Vidigal Filho (2000) que verificou o comportamento de cultivares de mandioca do estado visando atender as necessidades da agroindústria da região Noroeste do Paraná.

Dada a importância do espaço geográfico da produção agrícola e a falta de estudos que verificaram essa relação para cultura de mandioca, destacam-se alguns trabalhos que fazem uma análise espacial da produtividade agrícola, a fim de consolidar a metodologia utilizada neste estudo.

Perobelli et al. (2007), interessados em entender a estrutura espacial do setor agrícola brasileiro, buscaram analisar os efeitos espaciais que exercem influência na produtividade agrícola da terra para os anos de 1991, 1997 e 2003. Concluíram que as microrregióes com alta (baixa) produtividade agrícola sáo vizinhas de outras microrregióes nas mesmas características, portanto, confirmaram a presença de tendência espacial na produtividade agrícola brasileira.

Levando em consideração a produtividade do Paraná, Felema et al. (2016) estudaram os aspectos espaciais do comportamento das três principais culturas do estado, que são o feijão, milho e soja para os anos de 2000 e 2001. Seus resultados afirmam que existe autocorrelação entre as regióes e que os agentes influenciam as produtividades nas regióes 
circunvizinhas, ou seja, regiôes de alta (baixa) produtividade são vizinhas de regiōes na mesma situação.

Para analisar a produtividade média do café nas 66 microrregiōes do estado de Minas Gerais, Almeida et al. (2006) realizaram análise espacial de dados para o ano de 2000 e 2004. Concluíram que há autocorrelação espacial para a produtividade do café entre as microrregióes mineiras e que a produção é geograficamente concentrada, sendo assim, investimentos em técnicas de plantio e tecnologias podem influenciar as regióes vizinhas.

Diniz et al. (2012) realizaram estudo para identificar o padrão locacional da produtividade média de laranja para os municípios do estado de São Paulo. Eles identificaram autocorrelação positiva, ou seja, os municípios com alta (baixa) produtividade são vizinhos de municípios que apresentam o mesmo padrão.

Tendo em vista a importância da mandioca no Paraná, o presente estudo busca um avanço no entendimento das peculiaridades agrícolas dessa cultura. Portanto, buscase verificar se há presença de autocorrelação nos dados da produção das microrregióes paranaenses e obter os determinantes dos agrupamentos da produtividade.

\section{METODOLOGIA}

A metodologia está dividida em dois grandes blocos: primeiramente buscou-se explicar as variáveis utilizadas no estudo, enquanto na segunda parte estarão expostos o instrumental de analises de dados espaciais.

\subsection{Descriçáo dos dados}

Para construção da variável produtividade da mandioca em relação à terra (variável de intensidade, na qual é indicada para análise espacial) foram utilizados os dados de quantidade produzida ( $\mathrm{t}$ ) e área plantada (há) da cultura da mandioca em cada município paranaense nos anos de 2009, 2013 e 2017, obtidos junto à Secretaria de Estado da Agricultura e do Abastecimento (SEAB). Para estimativa e análise dos dados, usou-se o software gratuito GEODA.

Para facilitar a análise espacial dos dados considerou-se a divisão do Paraná em 10 mesorregióes (Figura 4) feita pelo Instituto Brasileiro de Geografia e Estatística (IBGE), considerando as características sociais e naturais de cada área, por meio das quais chegou-se a seguinte divisão:

- Mesorregião Centro Ocidental Paranaense: formada por 25 municípios;

- Mesorregião Centro Oriental Paranaense: formada por 14 municípios;

- Mesorregiáo Centro-Sul Paranaense: formada por 29 municípios;

- Mesorregião Metropolitana de Curitiba: formada por 37 municípios;

- Mesorregião Noroeste Paranaense: formada por 61 municípios;

- Mesorregião Norte Central Paranaense: formada por 79 municípios;

- Mesorregião Norte Pioneiro Paranaense: formada por 46 municípios; 
- Mesorregião Oeste Paranaense: formada por 50 municípios;

- Mesorregiáo Sudeste Paranaense: formada por 21 municípios;

- Mesorregião Sudoeste Paranaense: formada por 37 municípios.

Figura 4. Localização Geográfica das Mesorregióes do estado do Paraná

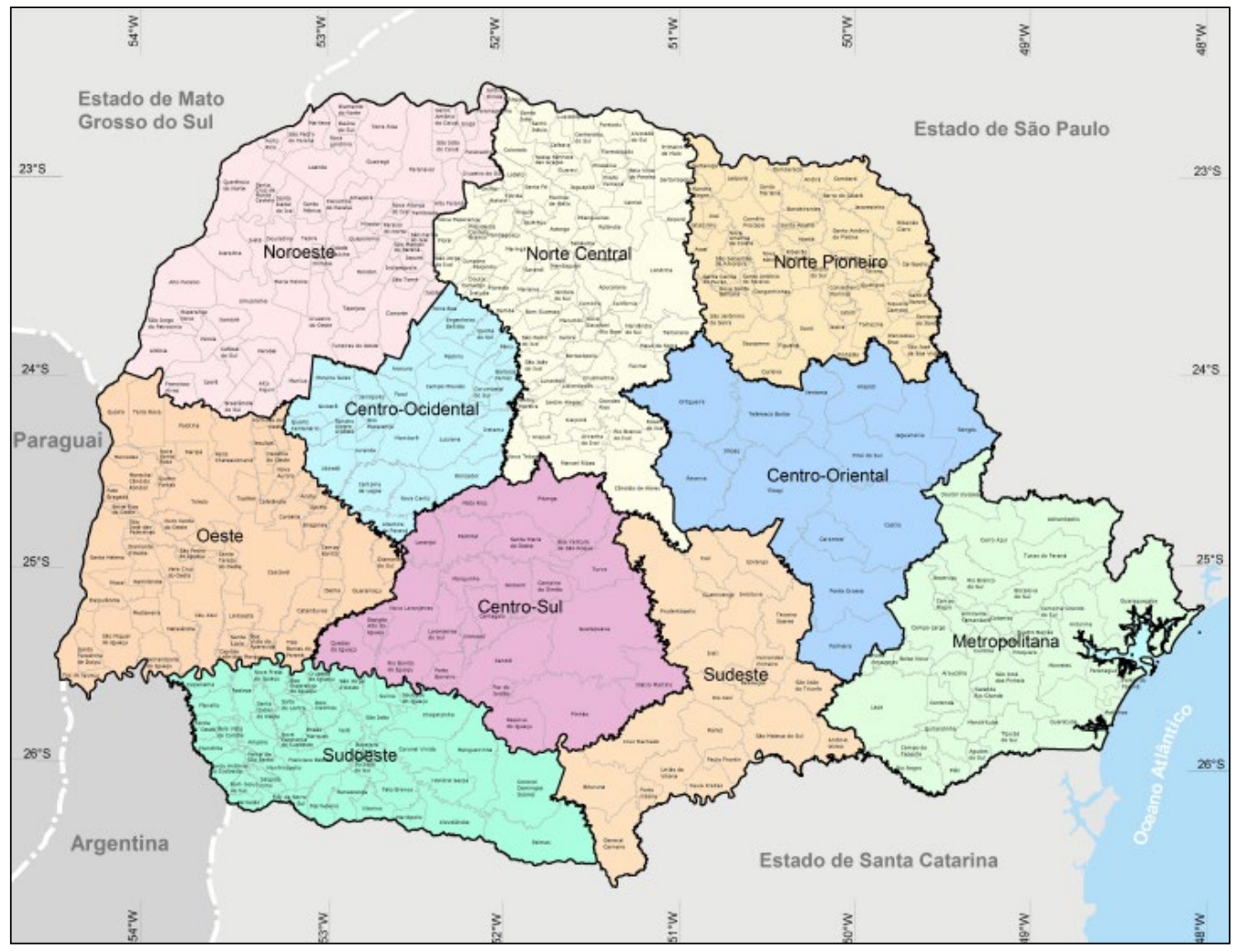

Fonte: Instituto Paranaense de Desenvolvimento Econômico e Social (2020).

\subsection{Autocorrelaçáo Espacial e Matrizes de Pesos Espaciais}

Esta pesquisa utiliza como metodologia a análise de dados espaciais (AEDE), partindo do pressuposto que as variáveis analisadas podem apresentar autocorrelação espacial. Esta pode ser entendida como a relação estabelecida entre valores similares e similaridades locacionais, desta forma, quando valores aleatórios de determinada localidade se agrupam, ocorre um processo de dependência espacial. A correlação espacial é definida positiva quando esses agrupamentos acontecem entres valores altos ou baixos, ou seja, quando altos (baixos) valores da região i são acompanhados por vizinhos $\mathrm{j}$ com valores altos (baixos). Por outro lado, é definida negativa quando as unidades espaciais são cercadas por unidades com valores significativamente distintos, assim, regióes que apresentam valores altos (baixos) são circundadas por vizinhos com valores baixos (altos) (ANSELIN; BERA, 1998; ALMEIDA, 2012). 
De acordo com Vieira (2009), ao considerar uma região onde só exista dependência unidirecional (Figura 5), ou seja, em que só existem vizinhos de "frente" e de "trás", recaise em uma situação em que a autocorrelação espacial seria idêntica a das séries de tempo. Contudo, o caso mais geral é ilustrado na Figura 6, em que as regióes estáo distribuídas em uma superfície bidimensional, e desta forma, apresentam dependência bidimensional.

Figura 5. Espaço com dependência unidirecional

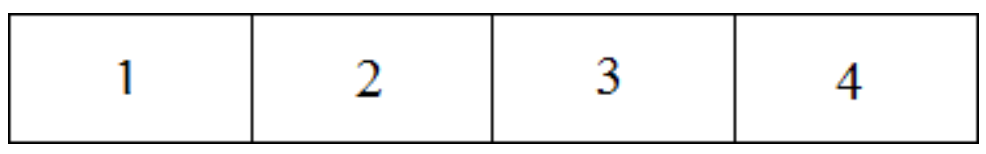

Fonte: Elaboração própria dos autores.

Figura 6. Espaço com dependência bidimensional

\begin{tabular}{|l|l|l|l|}
\hline 1 & 2 & 3 & 4 \\
\hline 5 & 6 & 7 & 8 \\
\hline
\end{tabular}

Fonte: Elaboração própria dos autores.

Para que seja possível analisar as interações entre as regióes usa-se uma representação gráfica dos dados espaciais em forma matricial, especificando as regiōes por meio da matriz de pesos espaciais (W). O critério de fronteira ou contiguidade é um dos principais métodos para se construir uma matriz W, na qual associa a posição de uma localidade às demais localidades no espaço. Para isso, atribui-se valor unitário para as regióes que compartilham fronteiras e valor nulo caso contrário (TYSZLER, 2006; ALMEIDA, 2012):

$$
w_{i j}=\left\{\begin{array}{lr}
1 & \text { se } i \text { e j possuem fronteira } \\
0 & \text { se i } \text { e j não possuem fronteira }
\end{array}\right.
$$

Desta forma, os dados de vizinhanças estáo relacionados com o valor de $w_{i j}$, na qual representa as relaçôes de vizinhança entre as regióes i e j. Se o valor assumido for $1\left(w_{i j}=1\right)$ os locais possuem uma fronteira, ou seja, são vizinhos, e valor $0\left(w_{i j}=0\right)$ para os locais que não possuem fronteira, não sendo vizinhos. Destaca-se que $w_{i i}$ sempre assumirá valor 0 , haja vista que nenhuma regiáo pode ser vizinha dela mesma (ALMEIDA, 2012).

$\mathrm{Na}$ Figura 7 estão apresentados os critérios de fronteira mais usados na literatura, conhecidos como "rainha", "torre" e "bispo", em alusão ao movimento das peças no jogo de xadrez. Dessa forma, o critério rainha, considera como vizinhos da região A os locais com fronteira ou vértices comuns (regiôes destacadas na Figura 7a). A partir do critério torre (Figura $7 \mathrm{~b}$ ), percebe-se que a regiáo $\mathrm{B}$ tem como vizinhos apenas os locais com fronteiras 
em comum. Por fim, o critério bispo (Figura 6c) considera apenas os vértices para definir os vizinhos de uma região (ALMEIDA, 2012).

Figura 7. Critérios de contiguidade

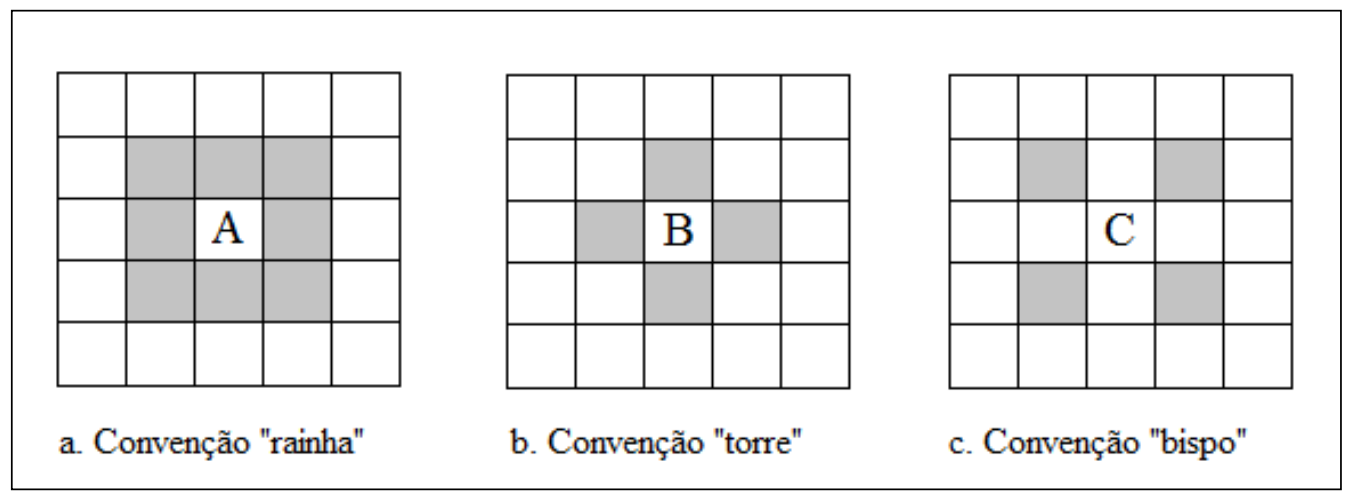

Fonte: Elaboração própria dos autores.

Um problema em relação a essas formas de matrizes reside no fato de que algumas localidades poderão apresentar um número muito maior de vizinhos que outras regiôes, ou seja, não é garantido uma conectividade balanceada. Para resolver esse problema, pode-se criar a matriz $\mathrm{W}$ de outras formas, sendo uma delas a matriz de $\mathrm{k}$ vizinhos mais próximos, em que está baseada nas distâncias entre as regiōes geográficas. Essa matriz busca combater o desbalanceamento da conectividade, em virtude de que todas as regiốes i apresentam o mesmo número de vizinhos (ALMEIDA, 2012):

$$
w_{i j}= \begin{cases}1 & \text { se } d_{i j} \leq \bar{d} \\ 0 & \text { se } d_{i j}>\bar{d}\end{cases}
$$

sendo $\bar{d}$ um valor de distância crítico.

De acordo com Silva, Borges e Parré (2013), a matriz W que melhor representa as características do fenômeno analisado será a que apresenta maior valor de defasagem espacial entre as variáveis estudadas.

\subsection{Análise Exploratória de Dados Espaciais}

Após o desenvolvimento da matriz de peso, se torna importante a verificação do efeito de dependência espacial, conforme já destacado, mas também o efeito de heterogeneidade espacial. Este fenômeno se manifesta com a ocorrência de instabilidade estrutural no espaço, podendo ser detectada a partir de coeficientes variáveis, de variância não constante, ou ainda, de formas funcionais diferentes (ALMEIDA, 2012).

A aplicação da análise exploratória de dados espaciais (AEDE) se explica por ser um método que objetiva retratar a distribuição espacial, os padrôes de associaçâo espacial (clusters espaciais), analisar a existência de diferentes regimes espaciais ou outras formas 
de instabilidade espacial e identificar observaçóes atípicas (outliers espaciais) (ANSELIN; BERA, 1998).

A AEDE é benéfica no estudo do processo de difusão espacial porque focaliza principalmente em encontrar padróes de autocorrelação espacial. A abordagem predominante, neste tipo de análise, é baseada nas estatísticas globais como I de Moran (ANSELIN; BERA, 1998; ALMEIDA, 2012).

Tradicionalmente, as medidas de autocorrelação espacial são divididas em duas categorias: global e local. A análise global considera que todos os elementos das matrizes W e Y são avaliadas, em conjunto, pelo cálculo de autocorrelação espacial. Já a análise local avalia a autocorrelação espacial relacionada a determinada unidade espacial (FISCHER; GETIS, 2010).

A autocorrelação espacial global pode ser calculada por meio da estatística $I$ de Moran (ALMEIDA, 2012):

$$
I_{t}=\left(\frac{n}{S_{0}}\right)\left(\frac{z^{\prime}{ }_{t} W z_{t}}{z^{\prime}{ }_{t} z_{t}}\right)
$$

em que $z_{t} z_{t}$ é o vetor de $n n$ observações para o ano $t t$ na forma de desvio em relação à média, W é a matriz de pesos espaciais e o termo $S_{0} S_{0}$ é um escalar igual à soma de todos os elementos de W.

A estatística $I$ de Moran mostra formalmente o grau de associação linear entre os vetores de valores observados no tempo $t\left(z_{t}\right) t\left(z_{t}\right)$ e a média ponderada dos valores $\mathrm{da}$ vizinhança, ou as defasagens espaciais $\left(W z_{t}\right)\left(W z_{t}\right)$. Se o valor de $I$ for maior (ou menor) do que o valor esperado $E(I)=-\frac{1}{n-1} E(I)=-\frac{1}{n-1}$ significa que há autocorrelação positiva (ou negativa) (ALMEIDA, 2012).

No momento que a matriz de pesos espaciais é normalizada na linha, isto é, quando os elementos de cada linha somam 1, a expressão (3) fica da seguinte forma (ALMEIDA, 2012):

$$
\mathrm{I}_{\mathrm{t}}=\left(\frac{z_{\mathrm{t}}^{\prime} \mathrm{Wz}_{\mathrm{t}}}{\mathrm{z}_{\mathrm{t}}^{\prime} \mathrm{z}_{\mathrm{t}}}\right) t=(1, \ldots, \mathrm{n})
$$

O $I$ de Moran propicia três tipos de informação: a) a significância provê a informação se os dados estáo distribuídos aleatoriamente ou não; b) o sinal positivo da estatística, desde que significativo, mostra que os dados estâo concentrados através das microrregiôes; e c) o sinal negativo indica a dispersão dos dados. A magnitude da estatística fornece a força da associação espacial: o $I$ de Moran pode variar de -1 a 1 . Quanto mais próximo de 1, mais forte é a concentraçáo, e quanto mais próximo de -1 , mais dispersos estão os dados (ANSELIN; BERA, 1998; ALMEIDA, 2012).

Contudo, as estatísticas globais desconsideram uma possível existência de instabilidade espacial, no sentido que se em algumas áreas específicas a autocorrelação espacial for positiva e em outras, negativa, o efeito, no geral, pode se anular e a autocorrelação não ser detectada (SILVA, BORGES, PARRÉ, 2013). Para que a instabilidade espacial seja 
considerada é necessário utilizar um coeficiente de autocorrelação espacial que seja capaz de detectar regimes de associação espacial que produzam um valor específico para cada área. Esse coeficiente pode ser determinado pelo I de Moran Local ou LISA, definido como (FISCHER; GETIS, 2010):

$$
I_{i}=z_{i} \sum_{j=1}^{i} W_{i j} z_{j}
$$

Uma abordagem adicional para a verificação da autocorrelação espacial é baseada no diagrama de dispersão de Moran. Este é dividido em quatro tipos de associação linear espacial: Baixo-Alto (BA), Alto-Alto (AA), Baixo-Baixo (BB) e Alto-Baixo (AB), como mostra a Figura 8 (ALMEIDA, 2012):

Figura 8. Ilustraçáo do diagrama de dispersão de Moran

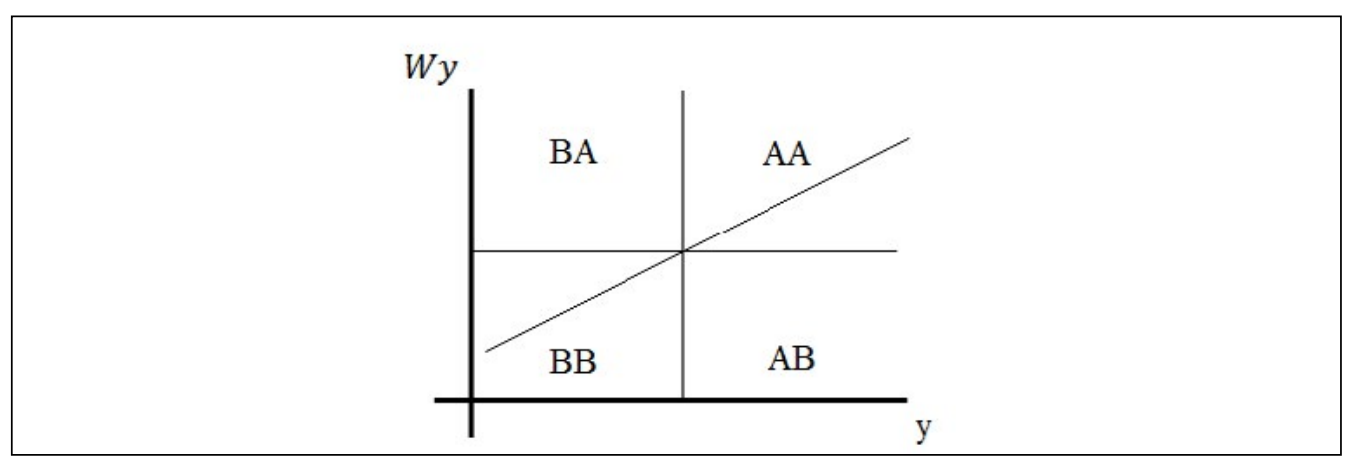

Fonte: Adaptado de Almeida (2012).

O diagrama de dispersão mostra a correlação linear entre a defasagem espacial ( $W y)$ da variável dependente e o valor da variável de interesse (y), padronizadas de tal modo que tenham média zero e variância unitária. $\mathrm{O}$ quadrante $\mathrm{AA}$ mostra áreas com altos valores para a variável de interesse, cercadas por regióes com valores acima da média para essa variável. O quadrante $\mathrm{BB}$ representa os locais com baixos valores para a variável dependente, circundados por locais com baixos valores. Já os quadrantes $\mathrm{BA}$ e $\mathrm{AB}$ representam, respectivamente, regióes com baixos (altos) valores para determinada variável, cercados por locais com altos (baixos) valores (ALMEIDA; PEROBELLI; FERREIRA, 2008).

É possível também averiguar a autocorrelação espacial global em um contexto bivariado (ALMEIDA, 2012):

$$
I^{z_{1} z_{2}}=\frac{n}{S_{0}} \frac{z_{1} W z_{2}}{z_{1} z_{2}}
$$

A equação (6) representa a estatística $I$ de Moran para duas variáveis diferentes, $z_{1} \mathrm{e}$ $z_{2}$. Dessa forma, é estudo se valores de uma variável possui relação com os valores de uma variável diferente nas regióes vizinhas. 


\section{RESULTADOS E DISCUSSÃO}

\subsection{Análise descritiva e univariada ( $I$ de Moran)}

Nas Figuras 9, 10 e 11 estão demonstrados os histogramas para a variável produtividade da mandioca nos anos 2009, 2013 e 2017, respectivamente. Por meio destas é possível analisar os valores mínimos e máximos da produtividade em cada período, além da média, mediana e desvio padrão.

Conforme a Figura 9, a produtividade da cultura da mandioca no ano de 2009 variou entre 0 e 45 t/ha, sendo a média do estado 20,22 t/ha com um desvio padráo de 5,39 . Ademais, cabe destacar o município de Nova Santa Rosa que apresentou a maior produtividade do estado, $45 \mathrm{t} / \mathrm{ha}$.

Figura 9. Histograma, média e desvio padrão da produtividade da terra no ano de 2009

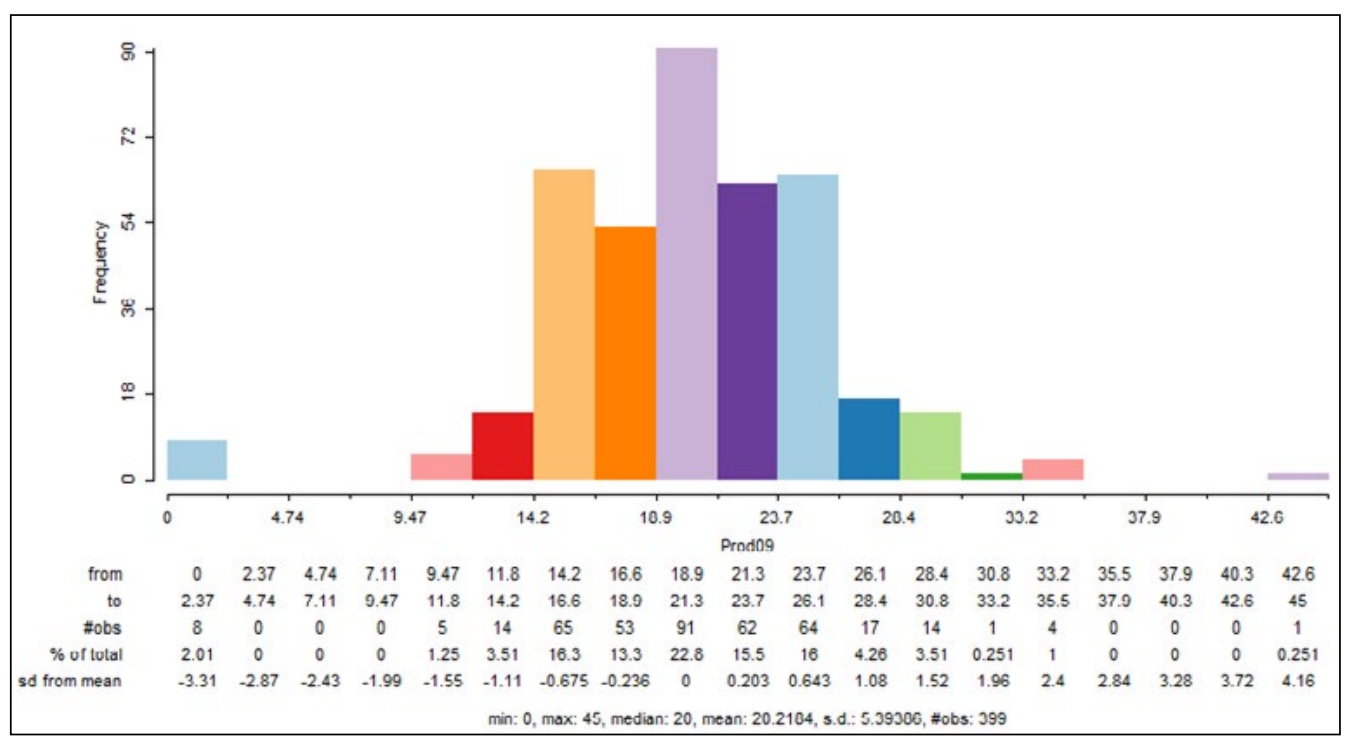

Fonte: Elaborado pelos autores a partir dos dados da pesquisa (2019).

Já no ano 2013 é possível verificar (Figura 10) que a produtividade variou entre 0 e $50 \mathrm{t} / \mathrm{ha}$, sendo que a média da produtividade do estado aumentou para 20,40 t/ha, com desvio padrão de 5,95. 
Figura 10. Histograma, média e desvio padrão da produtividade da terra no ano de 2013

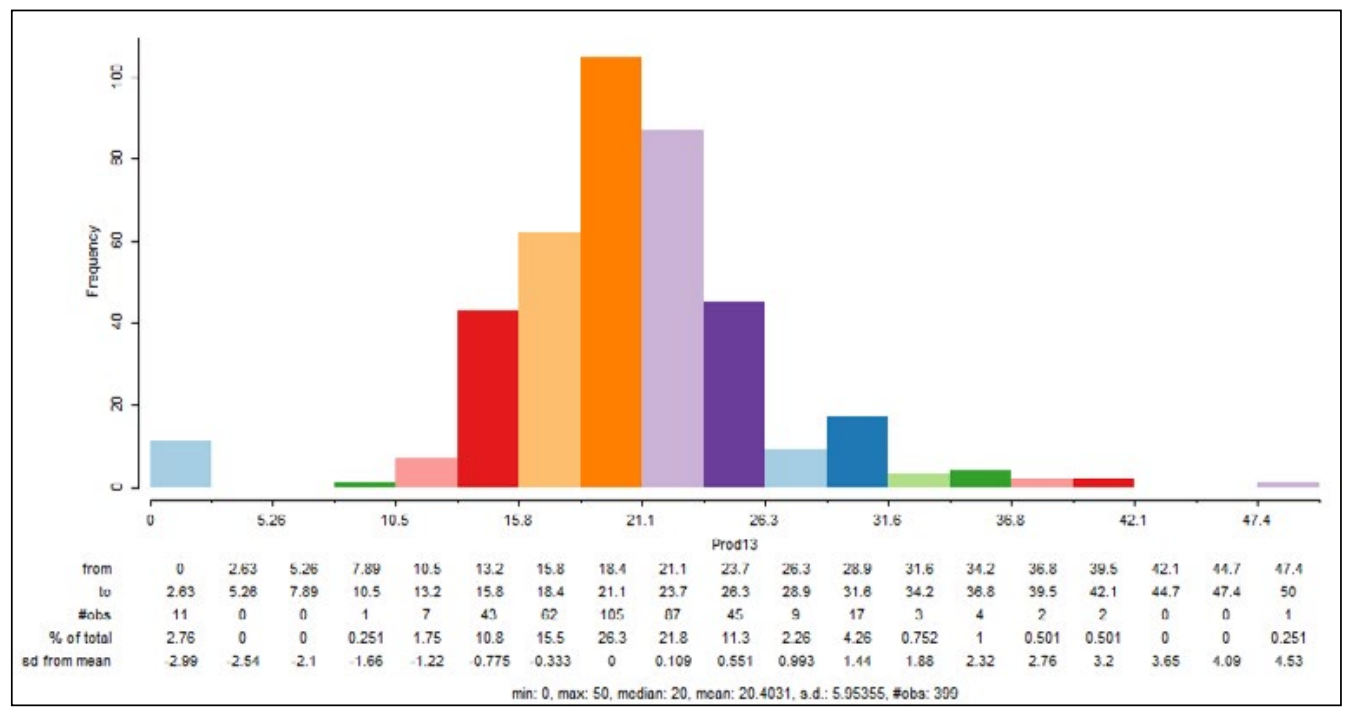

Fonte: Elaborado pelos autores a partir dos dados da pesquisa (2019).

No ano de 2017, a partir da Figura 11, observa-se que a produtividade variou entre 0 e $35 \mathrm{t} / \mathrm{ha}$, com uma média de 20,91 t/ha e desvio padrão de 4,68. Evidencia-se que a produtividade máxima diminui em 2017, comparando-se com 2009 e 2013, no entanto, a produtividade média do estado aumentou no último ano analisado. Por fim, destacase o município de Nova Santa Rosa, que novamente apresentou os maiores níveis de produtividade do estado do Paraná, tanto em 2013 (50 t/ha) quanto em 2017 (35 t/ha).

Figura 11. Histograma, média e desvio padrão da produtividade da terra no ano de 2017

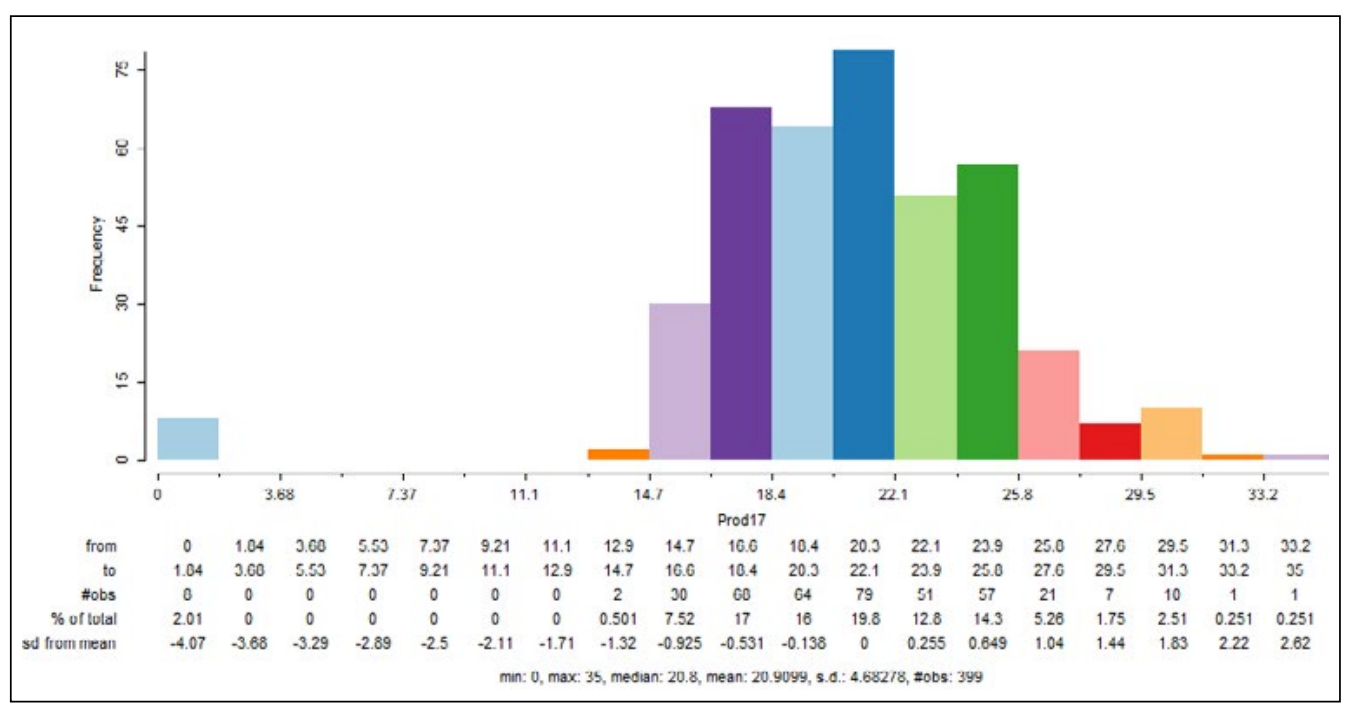

Fonte: Elaborado pelos autores a partir dos dados da pesquisa (2019). 
Partindo para a análise exploratória de dados espaciais (AEDE) da produtividade da cultura da mandioca, especificamente a estatística $I$ de Moran global, demonstradas na Tabela 3 e Figura 12 (diagrama de dispersão de Moran), observa-se que as estatísticas apresentaram autocorrelação espacial positiva, sendo estatisticamente significativas para os três anos considerados $(2009,2013$ e 2017). No entanto, percebe-se que a autocorrelaçáo espacial parece estar diminuindo com o passar do tempo.

Tabela 3. I de Moran, Valor Esperado, Desvio Padrão e Pseudo-Valor P - Análise univariada

\begin{tabular}{lcccc}
\hline & $I$ de Moran & VE & DP & Valor-p \\
\hline PROD09 & 0,5756 & $-0,0025$ & 0,0319 & 0,001 \\
PROD13 & 0,5083 & $-0,0025$ & 0,0300 & 0,001 \\
PROD17 & 0,3229 & $-0,0025$ & 0,0305 & 0,001 \\
\hline
\end{tabular}

Fonte: Elaborado pelos autores a partir dos dados da pesquisa (2019).

Nota: Pseudo-significância baseada em 999 permutaçôes aleatórias.

Figura 12. Diagrama de dispersão de Moran - Análise univariada

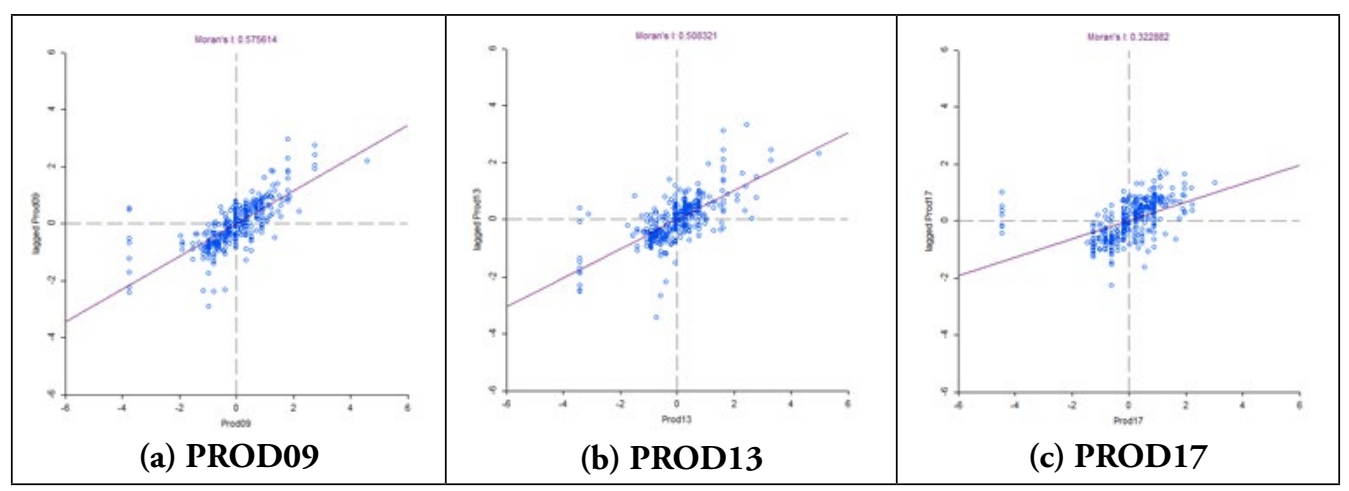

Fonte: Elaborado pelos autores a partir dos dados da pesquisa (2019).

$\mathrm{Na}$ Figura 13 estâo apresentados os clusters da estatística LISA para a variável produtividade da mandioca em relação à terra no ano de 2009, 2013 e 2017. Verifica-se que, de fato, há presença de autocorrelaçáo espacial positiva, pois a maior parte dos cluster representados foram AA e BB. Além disso, percebe-se que ao longo do tempo o estado diminui suas regióes $\mathrm{BB}$ gradativamente, comparando-se os anos analisados. No entanto ao analisar as regióes AA, nota-se que de 2009 a 2013 ocorre diminuição desses agrupamentos, enquanto que de 2013 a 2017 essas regióes voltaram a aumentar, superando o primeiro ano da análise.

Nota-se, ainda, que em 2009 as regióes AA se estendem do Oeste, Noroeste e Norte Central paranaense, apresentando pequeno grupo de clusters na regiāo Norte Pioneiro do estado. Com o passar dos anos (2013 e 2017), os clusters AA continuam concentrados, principalmente, nas quatro regióes paranaenses com aumento significativo na regiáo Norte Pioneiro. Ademais, percebe-se o surgimento de grupos AA na regiáo Centro Ocidental. 
Observa-se pequeno aumento desses agrupamentos no estado, passando de 55 em 2009 para 57 em 2017.

Como observado os clusters AA se concentram em grande parte nas regióes Oeste, Noroeste e Norte paranaense. Esse resultado pode estar associado com o importante parque industrial presente nessas regiôes, na qual apresentam cerca de 42 fábricas de féculas e 50 farinheiras. Por conta dessas industrias, os produtores tendem a manter lavouras mais intensivas em tecnologia e com maiores áreas de produção (GROXKO, 2017). Conforme dados da SEAB (2019), essas regióes concentram aproximadamente $78,4 \%$ da área plantada e em torno de $80,8 \%$ da produção de mandioca do estado em 2017. Apresentam, ainda, altas taxas de produtividade, sendo o Oeste paranaense a mesorregiáo com maior performance em seus rendimentos de mandioca plantada $(25,08 \mathrm{t} / \mathrm{ha})$.

Figura 13. Clusters - Produtividade da mandioca em relação à terra - Análise univariada

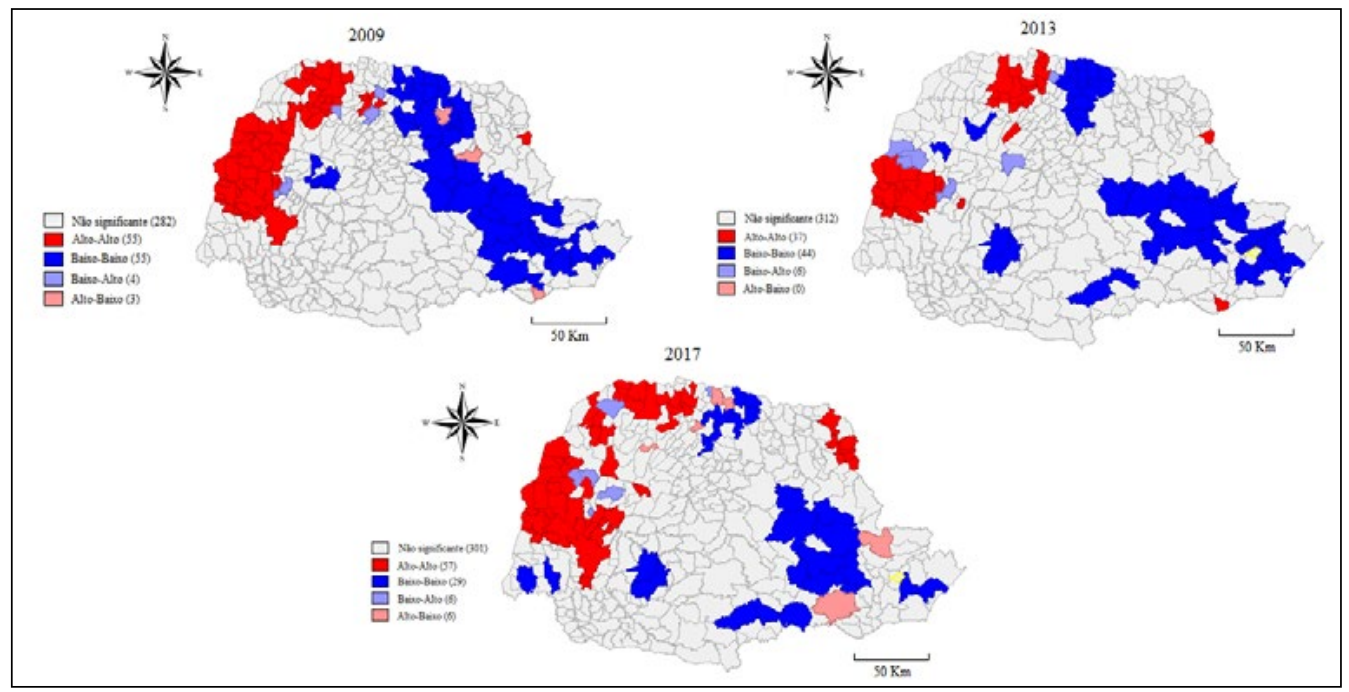

Fonte: Elaborado pelos autores a partir dos dados da pesquisa (2019).

Sobressai-se, também, a mesorregiáo Centro Ocidental paranaense, que apresentou a terceira maior produçáo de mandioca do estado e a quarta maior produtividade. Esse forte desempenho da região pode explicar o surgimento dos clusters AA no ano de 2017.

Conforme Groxko (2016), nas áreas em que as produçôes de mandioca são destinadas para o abastecimento das fecularias e farinheiras, torna-se necessário maiores produçóes e a utilização de tecnologias nas lavouras. Os produtores buscam orientaçóes de especialistas na área, procuram usar adubos adequados, realizam análise no solo entre outros métodos para melhorar cada vez mais a produtividade da terra.

Por outro lado, com relação aos clusters BB (Figura 13), verifica-se que em 2009 estavam concentrados nas regiôes Centro Ocidental, Noroeste, Norte Central, Norte Pioneiro, Centro Oriental e Metropolitana de Curitiba. Ao longo dos anos os agrupamentos BB diminuíram significativamente, passando de 55 no primeiro ano para 29 em 2017. Outrossim, no último ano perdem-se grande parte dos clusters registrados no Noroeste e 
Metropolitana de Curitiba e as regióes Centro Ocidental e Norte Pioneiro deixaram de apresenta-los. Por fim, em 2017, Oeste, Centro-Sul e Sudeste paranaense passaram a agrupar esses agrupamentos.

No estado do Paraná, de acordo com dados da SEAB (2019), cerca de 97,9\% dos municípios possuem lavouras de mandioca. No entanto, nas áreas onde a produção não é destinada ao abastecimento das indústrias de fécula e farinha, tendem a ser destinadas para o consumo humano ou de animais. Assim, as lavouras utilizam menor escala de produçáo e são menos intensivos em tecnologia, acarretando em menor produtividade (GROXKO, 2017). Groxko (2016) apresenta como exemplo o caso da regiáo metropolitana de Curitiba que aumentou consideravelmente, nos últimos anos, a produção de mandioca para uso familiar, por meio da produção de raiz cozida ou na forma de tapioca, que tem como matéria prima o polvilho azedo.

\subsection{Análise bivariada}

$\mathrm{Na}$ Tabela 4 e na Figura 14 são apresentadas a estatística I de Moran bivariada e o diagrama de dispersão, respectivamente, com o objetivo de se verificar a autocorrelação espacial em determinado período de tempo. Observa-se que há autocorrelação espacial temporal positiva, ou seja, agrupamentos com alta produtividade no ano de 2017 eram rodeados por agrupamentos com alta produtividade também em 2009. Da mesma forma, os clusters com baixa produtividade em 2017 tinham como vizinhos clusters de baixa produtividade no ano de 2013.

Tabela 4. I de Moran, Valor Esperado, Desvio Padrão e Pseudo-Valor P - Análise bivariada

\begin{tabular}{lcccc}
\hline & $I$ de Moran & VE & DP & Valor-p \\
\hline PROD17 x PROD09 & 0,3748 & $-0,0021$ & 0,0245 & 0,001 \\
PROD17 x PROD13 & 0,3725 & $-0,0018$ & 0,0255 & 0,001 \\
\hline
\end{tabular}

Fonte: Elaborado pelos autores a partir dos dados da pesquisa (2019).

Nota: Pseudo-significância baseada em 999 permutaçóes aleatórias. 
Figura 14. Diagrama de dispersão de Moran - Análise bivariada

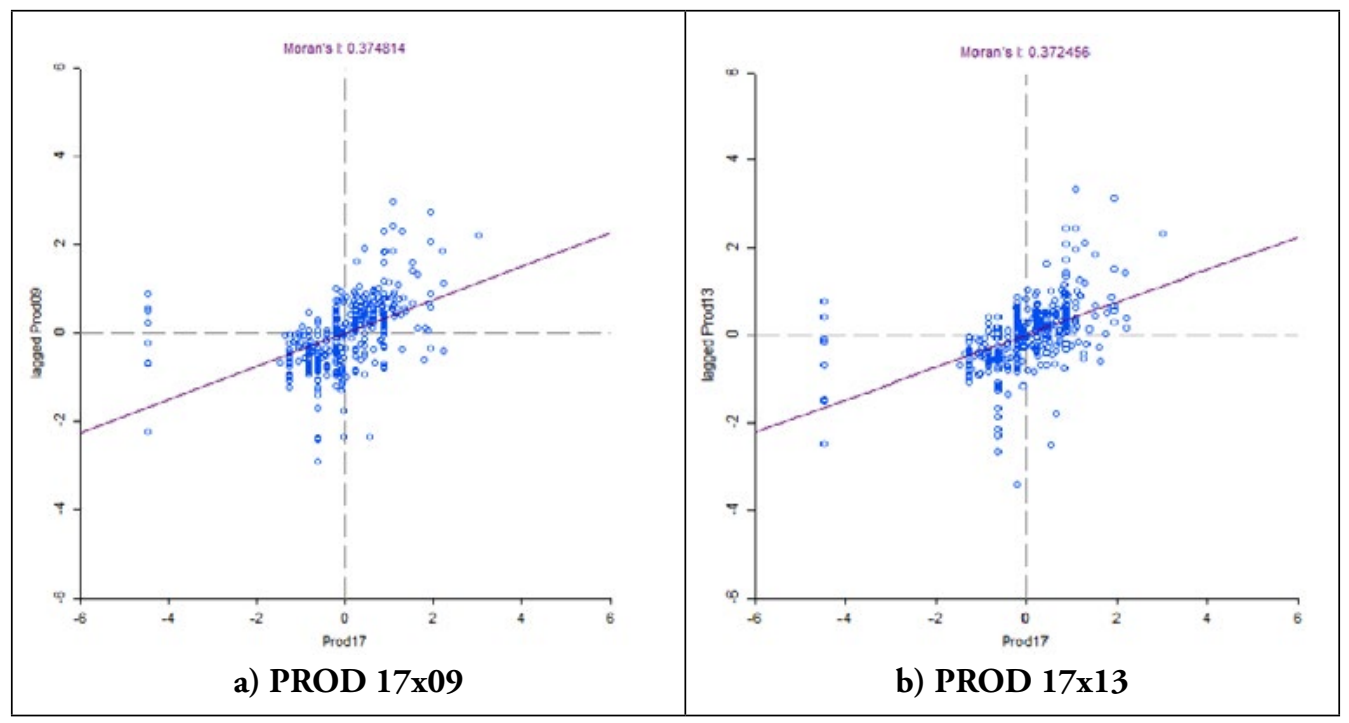

Fonte: Elaborado pelos autores a partir dos dados da pesquisa (2019).

Conforme abordado por Perobelli et al. (2007), a produtividade média agrícola está associada com diferentes insumos, como o avanço tecnológico, pesquisa e desenvolvimento agrícola, fatores que apresentam como características a cumulatividade e a dispersão no tempo e espaço. Dessa forma, torna-se coerente encontrar autocorrelação espacial temporal positiva, como foi observado nessa pesquisa.

Na Figura 15 é apresentada os agrupamentos de produtividade da cultura da mandioca no ano de 2017 relacionada aos de 2013 e 2009 defasados espacialmente. Percebese que ao analisar a produtividade desse produto em 2017 com a produtividade de 2009, os clusters se aproximam da análise univariada de 2009. Verifica-se, ainda, que o mesmo ocorre com a análise do ano de 2017 com o ano de 2013. Assim, observa-se que o tempo exerce importante influência na disposição espacial, apresentando certo nível de inércia (mesmo com efeitos de transbordamento e desaparecimento de agrupamentos), ou seja, grande parte dos clusters com alta (baixa) produtividade em 2017, também apresentavam alta (baixa) produtividade nos anos anteriores em seus vizinhos. Esse resultado está relacionado com a influência das fábricas de féculas e farinhas, presentes nas regiōes Oeste, Noroeste e Norte, para o alto nível de produtividade dessa cultura. 
Figura 15. Clusters - Produtividade da mandioca em relação à terra - Análise bivariada

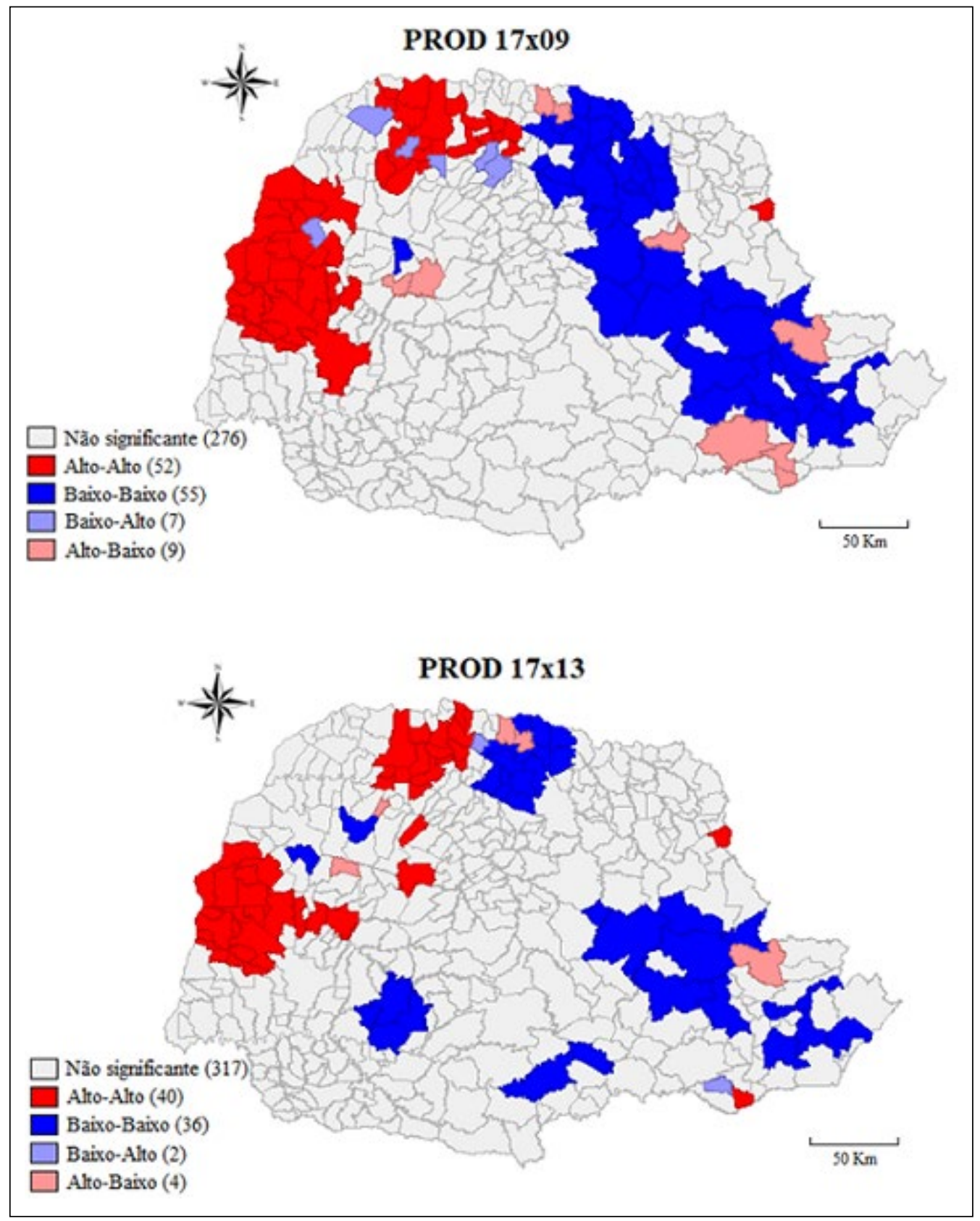

Fonte: Elaborado pelos autores a partir dos dados da pesquisa (2019). 


\section{CONSIDERAÇÓES FINAIS}

A pesquisa ora apresentada mostra a importância econômica da cultura na mandioca no estado do Paraná, principalmente nas regióes Oeste, Noroeste e Norte onde as produçóes são destinadas para o abastecimento das fecularias e farinheiras. Da análise descritiva foi possível afirmar que a média da produtividade da mandioca está aumentando, mesmo estando concentrada em algumas regióes do estado.

A análise espacial permite observar que com o passar do tempo a alta produtividade se concentra nas regióes Oeste, Noroeste e Norte, por conta da presença das indústrias de farinha e fécula. Nessas regióes, os produtores procurar utilizar adubos adequados, realizam análise do solo, buscam orientação com especialistas, além de outros métodos para melhorar cada vez mais a produtividade da terra.

Nas demais regiōes do estado, notou-se a predominância de clusters BB, pois nessas áreas a produçáo de mandioca tende a ser destinada para o consumo humano ou de animais. Assim, as lavouras utilizam menor escala de produção e são menos intensivos em tecnologia, acarretando em menor produtividade.

Os resultados da análise bivariada inferem que os dados apresentam autocorrelaçáo espacial temporal, ou seja, o tempo também influencia a estrutura dos dados. Nesse caso, os municípios com alta (baixa) produtividade em 2017 estavam cercados por municípios com alta (baixa) produtividade em 2009 e 2013, já que o $I$ de Moran foi maior que seu valor esperado. A autocorrelaçáo espacial positiva está de acordo com a literatura, já que a produtividade agrícola depende de fatores cumulativos.

É importante ressaltar a importância das indústrias de féculas e farinhas nas regiōes Oeste, Noroeste e Norte paranaense para o alto nível de produtividade da cultura da mandioca no estado, sendo necessário encontrar mecanismos para aumentar a produtividade nas demais regiôes. Para pesquisas futuras, recomenda-se estudar o efeito dessa produtividade sobre os rendimentos de lavouras destinadas às indústrias e de agricultores pertencentes à agricultura familiar no Paraná.

\section{REFERÊNCIAS}

AGUIAR, Eduardo Barreto et al. Efeito da densidade populacional e época de colheita na produçâao de raízes de mandioca de mesa. Bragantia, v. 70, n. 3, p.561-569, 2011.

ALMEIDA, E. S., PACHECO, G. O., PATROCÍNIO, A. P. B., DIAS, S. M. Produtividade do café em Minas Gerais: uma análise espacial. In: Congresso Brasileiro de Economia e Sociologia Rural, Fortaleza, 2006. Anais. Fortaleza: Sociedade Brasileira de Economia e Sociologia Rural (SOBER), 2006.

ALMEIDA, E. S.; PEROBELLI, F. S.; FERREIRA, P.G. Existe convergência da produtividade agrícola espacial no Brasil? Revista de Economia e Sociologia Rural, v. 46, p. 31-52, 2008.

ALMEIDA, E. Econometria Espacial. Campinas-SP. Alínea, 2012. 
ALVES, A. A. C. Cassava botany and physiology. In R. J. Hillocks, J. M. Thresh, \& A. C. Bellotti. Cassava: biology, production and utilization (p. 67-89). Oxon, UK: CABI Publishing, 2002.

ANSELIN, L.; BERA, A. K. Spatial dependence in linear regression models with an introduction to spatial econometrics. Statistics Textbooks and Monographs, v. 155, p. 237-290, 1998.

BIFFE, D. F.; CONSTANTIN, J.; OLIVEIRA JUNIOR, R. S.; FRANCHINI, L. H. M.; RIOS, F. A.; BLAINSKI, E.; CAVALIERI, S. D. Período de interferência de plantas daninhas em mandioca (Manihot Esculenta) no noroeste do Paraná. Planta Daninha, v. 28, n. 3, p.471-478, 2010.

COÊLHO J. D. Produção de Mandioca - Raiz, Farinha e Fécula. Escritório Técnico de Estudos Econômicos do Nordeste (ETENE), n.44, 2018.

DINIZ, S. S.; CAMARA, M. R. G.; MASSAMBANI, M. O.; ANHENESI, J. A. R.; SESSO FILHO, H. A. Análise Espacial da Produtividade da Laranja dos Municípios do Estado de Sáo Paulo: 2002-2010. Anais. Vitória: Sociedade Brasileira de Economia e Sociologia Rural (SOBER), 2012.

FAOSTAT. Food and Agriculture Organization of the United Nations. Production. Disponível em: <http://www.fao.org/faostat/en/\#data>. Acesso em 04 jul. 2019.

FELEMA, J.; DE MEDEIROS, E. R.; FERREIRA, C. R.; DA CAMARA, M. R. G.; DO NASCIMENTO, S. P. Um estudo da produtividade do feijão, do milho e da soja na agricultura paranaense, nos anos de 2000 e 2010: uma análise espacial. Ensaios FEE, Porto Alegre, v. 43, n. 36, p.817-842, mar. 2016.

FISCHER, M. M.; GETIS, A. Handbook of Applied Spatial Analysis. Springer Berlin Heidelberg, 2010.

GROXKO, M. Mandioca - Análise da Conjuntura Agropecuária. Secretária de Estado da Agricultura e do Abastecimento (SEAB). Departamento de Economia Rural (DERAL). 2016. Disponível em: <http://www.agricultura.pr.gov.br/arquivos/File/deral/ Prognosticos/2017/Mandioca_2016_17.pdf>. Acesso em 16 ago. 2019.

GROXKO, M. Prognóstico Mandioca 2017/18. Secretária de Estado da Agricultura e do Abastecimento (SEAB). Departamento de Economia Rural (DERAL). 2017.

Disponível em: <http://www.agricultura.pr.gov.br/arquivos/File/deral/Prognosticos/2018/ Mandioca_2017_18.pdf>. Acesso em 16 ago. 2019.

HOWELER, R.; LUTALADIO, N.; THOMAS, G. Save and grow: cassava. A guide to sustainable production intensification. FAO, Roma, 2013. 
IBGE - Instituto Brasileiro de Geografia e Estatística. Produçáo Agrícola Municipal (PAM). 2019. Disponível em: <https://sidra.ibge.gov.br/tabela/1612>. Acesso em 04 jul. 2019.

IBGE - Instituto Brasileiro de Geografia e Estatística. Levantamento Sistemático da Produçáo Agrícola. 2020. Disponível em: <https://sidra.ibge.gov.br/tabela/1618> Acesso em 01 ago. 2020.

INSTITUTO PARANAENSE DE DESENVOLVIMENTO ECONÔMICO E SOCIAL. Regióes Geográficas (Lei Estadual 15.825/08 - Paraná). 2020. Disponível em: <http://www.ipardes.pr.gov.br/>. Acesso em 04 de mar. 2020.

MODESTO JÚNIOR, M. S.; ALVES, R. N. B.; SILVA, E. S. A. Produtividade de mandioca de agricultores familiares do baixo Tocantins, Pará. Revista Raízes e Amidos Tropicais, Botucatu, v. 5, n. 8, p.522-528, jul. 2009.

PEROBELLI, F. S.; ALMEIDA, E. S. D.; ALVIM, M. I. D. S. A.; FERREIRA, P. G. C. Produtividade do setor agrícola brasileiro (1991-2003): uma análise espacial. Nova Economia, v. 17, n. 1, p.65-91, abr. 2007.

SEAB - Secretaria de Estado da Agricultura e do Abastecimento. Produçáo Agropecuária. Disponível em: <http://www.agricultura.pr.gov.br/modules/conteudo/ conteudo.php?conteudo=137>. Acesso em 04 jul. 2019.

SILVA, A. F.; SANTANA, L. M. D.; FRANÇA, C. R.; MAGALHÁES, C. A. D. S.; ARAÚJO, C. R. D.; AZEVEDO, S. G. D. Produção de diferentes variedades de mandioca em sistema agroecológico. Revista Brasileira de Engenharia Agrícola e Ambiental, Campo Grande, v. 13, n. 1, p.33-38, mar. 2009.

SILVA, D.V.; SEDIYAMA, T. S.; SILVA, D. V.; FRANÇA, A. C.; FERREIRA, E. A. Manejo de plantas daninhas na cultura da mandioca. Planta Daninha, v. 30, n. 4, p.901910, dez. 2012.

SILVA, L. N. S.; BORGES, M. J.; PARRÉ, J. L. Distribuição Espacial da Pobreza no Paraná. Revista de Economia, v. 39, n. 3, 2013.

TYSZLER, M. Econometria espacial: discutindo medidas para a matriz de ponderação espacial. 2006. 141 p. Dissertação (Mestrado em Administração Pública e Governo). Escola de Administração de Empresas de São Paulo, Fundação Getúlio Vargas, 2006.

VIDIGAL FILHO, P. S. et al. Avaliação de cultivares de mandioca na Região Noroeste do Paraná. Bragantia, v. 59, n. 1, p.69-75, 2000.

VIEIRA, R. S. Crescimento econômico no Estado de Sáo Paulo: uma análise espacial. Editora UNESP, 2009. 